\title{
PROSPEK PENGGUNAAN MESIN PANEN PADI COMBINE HARVESTER DI DESA KARANG MULYA SEMENDAWAI TIMUR OKU TIMUR
}

\author{
(Sudarti)
}

\begin{abstract}
The purpose of this study is to: (1) To calculate the cost, revenue and income obtained from the use of Combine Harvester rice harvesting machine in Karang Mulya Village, East Semendawai District, OKU Timur Regency, (2) To analyze the feasibility of using Combine harvest machine Harvester in Karang Mulya Village, East Semendawai Sub-district, OKU Timur Regency, (3) To know the prospect of Harvesters Combine Harvester harvesting machine in Karang Mulya Village, East Semendawai District, especially in East OKU Regency. The research will be conducted in Karang Mulya Village, East Semendawai District, OKU Timur Regency. Determination of the location is deliberately determined because in the village of Karang Mulya most of the population work as rice farmers. When harvest season comes the farmers are constrained by the limited labor harvest so that there are respondents who took the initiative to seek the harvesting machine harvesting rice harvester. The research will be conducted in March 2015. The study found that the total production cost incurred by the respondents in the Harvesting Combine Harvester harvesting machine business in Karang Mulya Village amounted to Rp 871,710,000, the business income was $R p$ 1,107,270,000 so the income received was Amounting to $R p$ 235,560,000. Harvesting machine harvesting Combine Harvester in Karang Mulya village feasible financially to be developed, it can be known from the calculation of business NPV value of Rp 109,848,197, IRR value is $58.10 \%$ and Net B/C value of 1,52 .
\end{abstract}

Key Words : Combine Harvester, Business Feasibility Study, Post-Harvest Countermeasures.

\section{PENDAHULUAN}

\section{A. Latar Belakang}

Padi sebagai tanaman yang dibudidayakan dengan pola tanam serentak, pada saat dipanen membutuhkan tenaga kerja yang sangat banyak agar panen dapat dilakukan tepat waktu. Kebutuhan tenaga kerja yang besar pada saat panen ini menjadi masalah pada daerah-daerah tertentu yang penduduknya sedikit. Oleh karena itu perlu dikembangkan sistem budidaya pertanian berbasis teknologi berupa mesin pemanen padi yang dapat mempermudah kerja petani (Barokah, N. I. 2001).

Sasaran pembangunan sektor pertanian ini adalah meningkatkan hasil pertanian untuk mendukung industri yang kuat. Usaha-usaha ke arah itu tidak akan dicapai apabila petani sebagai pelaku utama tidak akan dicapai apabila petani sebagai pelaku utama tidak dibantu dan dilengkapi dengan sarana produksi misalnya alat dan mesin pertanian. Masalah pasca panen yang dihadapi oleh petani adalah rendahnya mutu dan tingginya tingkat kehilangan. Buruknya pasca panen menyebabkan kelemahan daya tawar petani (bargaining position). Penanganan pasca panen merupakan kegiatan utama untuk meningkatkan dan mempertahankan mutu. Prosesnya merupakan rangkaian yang komplek, tidak hanya ditentukan oleh masalah teknis saja tetapi juga melibatkan masalah sosial dan ekonomi yang menyangkut berbagai sektor dan disiplin ilmu.

Adapun peranan alat pertanian secara umum adalah sebagai berikut:

a) Meningkatkan produktifitas tenaga dan lahan usahatani.

b) Meningkatkan dan meratakan pendapatan petani, melalui cara :

1) Memperbaiki penanganan pasca panen.

2) Pengolahan hasil dan

3) Pemasaran.

c) Memperluas kesempatan kerja.

d) Menekan ongkos produksi

e) Mengurangi kejerihan (kelelahan) kerja petani.

f) Mendukung upaya pelestarian lingkungan serta energi pertanian.

Peningkatan kuantitas hasil dengan upaya menekan kehilangan dan kualitas produksi tanaman pangan, khususnya komoditas padi terus digalakkan oleh pemerintah dalam rangka meningkatkan dan melestarikan swasembada beras yang pernah dicapai pada tahun 1984 . Dalam hal ini pemerintah telah menyebar luaskan informasi teknologi perbaikan penanganan pasca panen melalui forum kampanye pasca panen, pendidikan dan pelatihan serta forum-forum lain 
yang menunjang perbaikan pasca panen. Tahap keberhasilan upaya tersebut dapat dilihat dengan terus meningkatkan penggunaan alsin (alat dan mesin) pasca panen di kalangan petani, yang salah satunya adalah yang disebut mesin perontok padi Threser dan Combine Harvester. (Suryodiningrat, 2005).

Sumatera Selatan merupakan provinsi yang memiliki program lumbung pangan nasional, hal ini tidak terlepas dari tersedianya potensi sumber daya lahan yang cukup variatif, mulai dari lahan sawah irigasi, tadah hujan, rawa pasang surut, lebak dan lahan kering. Produksi padi Sumatera Selatan pada tahun 2012 yaitu sebesar 3.859.132 ton gabah kering giling (GKG) dengan jumlah penduduk 8.5428.719 jiwa konsumsi beras perkapita sebesar $105(\mathrm{~kg})$. Sumatera Selatan terdapat beberapa daerah penghasil padi yang relatif besar, antara lain Kabupaten Musi Banyu Asin, Kabupaten Musi Rawas, Kabupaten Muaraenim, Kabupaten Prabumulih, Kabupaten OKI, dan Kabupaten OKU Timur ( BPPKP OKU Timur, 2012). Kabupaten OKU Timur terus menunjukan
eksisitas provitastensinya dibidang pertanian dengan menjadi daerah penyumbang produksi beras terbesar di Provinsi Sumatera Selatan bahkan ditingkat Nasional. Sasaran bidang petanian yang akan dicapai dalam dua periode yakni priode 2005-2010 yang menitik beratkan pada upaya peningkatan produksi beras nasional diatas 5\%. Periode kedua 2010-2015 dititik beratkan pada pencapaian produksi 1 juta ton gabah kering giling (GKG) pada panen tahun 2015. Pada tahun 2012 luas tanam mencapai 129.623 ha, dengan luas panen 105.862 ha. Produksi padi GKG mengalami kenaikan pada jumlah produksi sebesar 569.448 ton dari tahun sebelumnya. Produksi padi di Kecamatan Semendawai Timur dengan luas tanam 3.778,7 ha dan luas panen 3.707 ha mencapai 118.461 ton GKG (BPPKP OKU Timur, 2012).

Tabel 1. Realisasi Luas Tanam, Luas Panen, dan Produksi Komoditi Padi Sawah Kabupaten OKU Timur Tahun 2012.

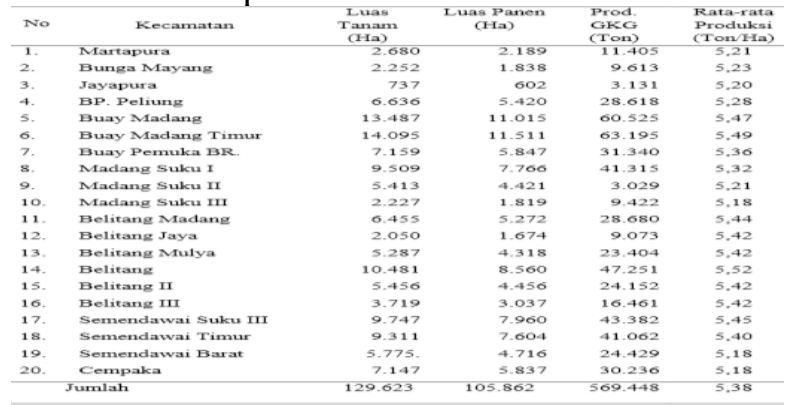

Sumber Data : BP2KP OKU Timur, 2012.
Berdasarkan data pada di atas diketahui bahwa luas tanam padi sawah di Kabupaten OKU Timur pada tahun 2012 adalah seluas $129.623 \mathrm{Ha}$ dengan luas panen mencapai $105.862 \mathrm{Ha}$ dan produksi GKP mencapai 569.448 ton sehingga di peroleh rata-rata produksi GKP adalah 5,38 ton/ha.

Desa Karang Mulya merupakan Desa yang sawahnya irigasi non teknis dan akan menjadi irigasi teknis di tahun 2017, sekarang masih tahap pembangunan di Kecamatan Semendawai Timur. Desa Karang Mulya memiliki luas lahan pada sawah irigsi non teknis dengan luas $472 \mathrm{Ha}$, Berdasarkan gambaran tersebut menggambarkan bahwa usahatani padi di Desa Karang Mulya, Kabupaten OKU Timur memiliki potensi yang cukup besar apabila dikelola dengan baik.

Kegiatan usahatani memiliki tujuan untuk meningkatkan produktivitas agar keuntungan menjadi lebih tinggi. Produksi dan produktivitas tidak lepas dari faktor-faktor produksi yang dimiliki petani untuk meningkatkan produksi hasil panennya. Faktor-faktor produksi yang dimiliki petani umumnya memiliki jumlah yang terbatas tetapi disisi lain petani juga ingin meningkatkan produksi usahataninya. Hal tersebut menuntut petani untuk menggunakan alat bantu mesin panen combine harvester untuk percepatan penanganan panen sehingga mempercepat penanaman kembali dan mengurangi tenaga kerja. Sebagian besar petani di Desa Karang Mulya, merupakan petani yang memiliki luas lahan sawah sehingga dalam pemanenan mengalami kesulitan untuk mencari tenaga kerja sehingga mengunakan alat bantu mesin panen combine harvester, sehingga mempercepat pasca panen dengan tercapainya efisiensi dalam penanganan pasca panen padi.

\section{B. Rumusan Masalah}

1. Berapa besar biaya, penerimaan dan pendapatan yang diperoleh dari penggunaan mesin panen padi Combine Harvester di Desa Karang Mulya Kecamatan Semendawai Timur Kabupaten OKU Timur.

2. Bagaimana kelayakan usaha penggunaan mesin panen padi Combine Harvester di Desa Karang Mulya Kecamatan Semendawai Timur Kabupaten OKU Timur.

3. Bagaimana prospek penggunaan mesin panen padi Combine Harvester di Desa Karang Mulya Kecamatan Semendawai Timur.

\section{Tujuan dan Kegunaan}

1. Untuk menghitung besarnya biaya, penerimaan dan pendapatan yang diperoleh dari 
penggunaan mesin panen padi Combine Harvester di Desa Karang Mulya Kecamatan Semendawai Timur Kabupaten OKU Timur.

2. Untuk menganalisis kelayakan usaha penggunaan mesin panen padi Combine Harvester di Desa Karang Mulya Kecamatan Semendawai Timur Kabupaten OKU Timur.

3. Untuk mengetahui prospek penggunaan mesin panen padi Combine Harvester di Desa Karang Mulya Kecamatan Semendawai Timur khususnya dan di Kabupaten OKU Timur pada umumnya.

\section{Model Pendekatan}

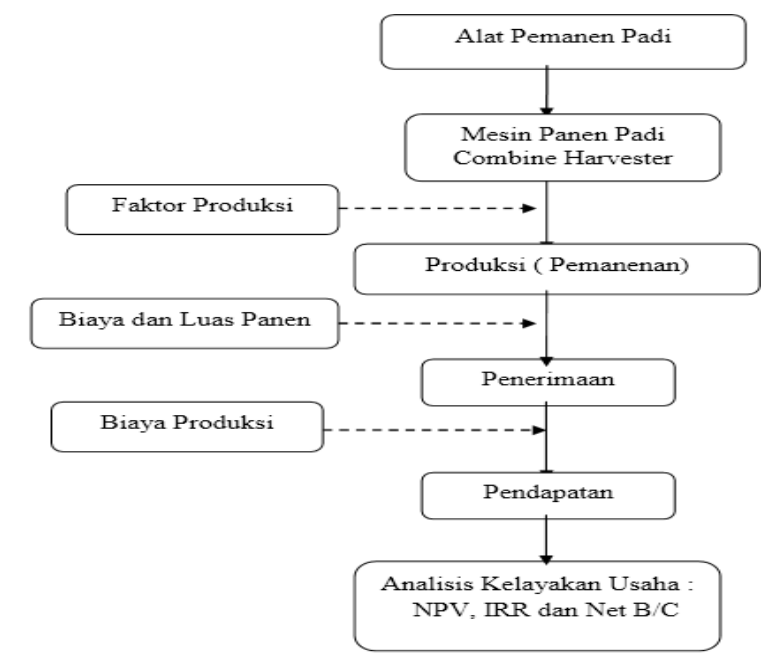

Keterangan :

$\longrightarrow$ : Proses

Gambar 1. Model pendekatan penelitian secara diagramatik

\section{METODOLOGI PENELITIAN}

\section{A. Tempat dan Waktu}

Penelitian akan dilaksanakan di Desa Karang Mulya Kecamatan Semendawai Timur Kabupaten OKU Timur. Penentuan lokasi tersebut di tentukan secara sengaja karena di Desa Karang Mulya sebagian besar penduduknya bekerja sebagai petani padi. Saat musim panen tiba petani terkendala dengan terbatasnya tenaga kerja panen sehingga ada responden yang berinisiatif untuk mengusahakan penyewaan mesin panen padi combine harvester. Penelitian akan dilaksanakan pada bulan Maret 2015.

\section{B. Metode Penelitian}

Metode yang telah dilakukan dalam penelitian ini adalah metode Studi Kasus (Case Study) yang bertujuan memperoleh gambaran yang lebih mendalam dari suatu objek yang diteliti. Menurut Nazir (2003), studi kasus atau penelitian kasus (case study) adalah penelitian tentang kasus subyek penelitian yang berkenaan dengan suatu fase spesifik atau khas dari keseluruhan personalitas. Subjek penelitian dapat berupa individu, kelompok, lembaga maupun masyarakat. Tujuan studi kasus adalah untuk memberikan gambaran secara detail tentang latar belakang, sifat serta karakter yang khas dari kasus atau individu yang kemudian dari sifat-sifat tersebut dijadikan suatu hal yang bersifat umum.

\section{Metode Penarikan Contoh}

Metode penarikan contoh dengan menggunakan metode sensus terhadap satu orang responden yaitu Bapak Putu Sri Waste yang mengusahakan penyewaan mesin panen Combine Harvester di Desa Karang Mulya.

\section{Metode Pengolahan Data}

Metode pengolahan data dilaksanakan dengan menganalisis data yang ada menggunakan analisis deskriptif kuantitatif yaitu suatu metode penelitian yang menggunakan angka yang kemudian diolah, dianalisis dan ditarik kesimpulan yang menggambarkan objek yang diteliti.

Untuk menjawab tujuan penelitian yang pertama yaitu untuk mengetahui berapa besar biaya pendapatan dan penerimaan dari usaha penyewaan mesin pemanen padi combine harvester dapat dihitung dengan rumus sebagai berikut :

1) Untuk mengetahui jumlah biaya produksi digunakan rumus :

$$
\mathrm{TC}=\mathrm{FC}+\mathrm{VC}
$$

$\mathrm{TC}=$ Total Cost $($ Biaya Total $)$

$\mathrm{FC}=$ Fixed Cost (Biaya Tetap)

$\mathrm{VC}=$ Variable Cost (Biaya variabel)

2) Untuk mengetahui jumlah penerimaan digunakan rumus :

$$
\mathrm{TR}=\mathrm{P} \times \mathrm{Q}
$$

$\mathrm{TR}=$ Total Revenue (Penerimaan)

$\mathrm{P}=$ Price (Harga)

$\mathrm{Q}=$ Quantum (Produksi)

3) Untuk mengetahui pendapatan digunakan rumus :

$$
\mathrm{I}=\mathrm{TR}-\mathrm{TC} \text {. }
$$

Keterangan :

$\mathrm{I}=$ Income (Pendapatan)

$\mathrm{TR}=$ Total Revenue (Penerimaan)

$\mathrm{TC}=$ Total Cost $($ Total Biaya $)$

4) Untuk menghitung uji kelayakan menggunakan rumus : 


$$
\mathrm{R} / \mathrm{C} \text { Ratio }=\frac{\mathrm{TR}}{\mathrm{TC}}
$$

Kriteria :

R/C Ratio > 1, maka usaha menguntungkan

$\mathrm{R} / \mathrm{C}$ Ratio $=1$, maka usaha impas

$\mathrm{R} / \mathrm{C}$ Ratio $<1$, maka usaha rugi

Untuk menjawab tujuan penelitian yang kedua dan ketiga yaitu untuk mengetahui kelayakan financial dan prospek usaha penyewaan mesin pemanen padi combine harvester dapat dihitung dengan analisis NPV, IRR dan Net B/C :

5) Untuk menghitung nilai kini bersih atau NPV dari suatu usaha digunakan rumus Compounding faktor, rumus tersebut digunakan untuk menghitung nilai kini terhadap uang di tahun yang berlalu.

$$
\mathrm{NPV}=\sum_{t=0}^{t=1} \frac{B_{\mathrm{t}}-\mathrm{C}_{\mathrm{t}}}{(1+\mathrm{i})^{t}}
$$

Keterangan:

$\mathrm{B}=$ Benefit (penerimaan)

$\mathrm{C}=\operatorname{cost}$ (biaya)

$\mathrm{i}=$ suku bunga yang berlaku

6) Untuk menghitung IRR (Internal Rate Of Return/Laju Keberhasilan Usaha), dapat menggunakan rumus berikut:

$\mathrm{IRR}=\mathrm{r} 1+\frac{\mathrm{NPV} 1}{(\text { NPV1-NPV2) }} \times(\mathrm{r} 2-\mathrm{-r} 1)$

Keterangan :

NPV 1 : Net present value (nilai kini bersih) yang bernilai positif

NPV 2 : Net present value (nilai kini bersih) yang bernilai negatif

r1: discount rate yang menghasilkan NVP 1

r1: discount rate yang menghasilkan NVP 2

7) Rumus yang di akan gunakan berikutnya dalam menentukan kelayakan pada usaha ini ialah Net B/C, Net B/C ini menunjukkan gambaran berapa kali lipat manfaat (benefit) yang diperoleh dari biaya (cost) yang dikeluarkan.

Apabila Net B/C > 0, maka proyek atau gagasan usaha yang akan didirikan layak untuk dilaksanakan. Demikian pula sebaliknya, apabila net $\mathrm{B} / \mathrm{C}<0$, maka proyek atau gagasan usaha yang akan didirikan tidak layak untuk dilaksanakan. Net B/C ratio merupakan manfaat bersih tambahan yg diterima proyek dari setiap 1 satuan biaya yg dikeluarkan :

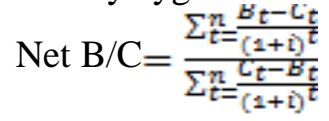

$B_{t}=$ Manfaat Benefit

$C_{t}=$ Biaya Pada Tahun Ke-t $i=$ Discount faktor

$t=$ Umur Proyek

Indikator Net B/C Ratio adalah :

- Jika Net B/C > 1, maka proyek layak (go) untuk dilaksanakan

- Jika Net $\mathrm{B} / \mathrm{C}<1$, maka proyek tidak layak (not go) untuk dilaksanakan

\section{HASIL DAN PEMBAHASAN}

\section{A. Analisis Biaya Usaha Penyewaan Mesin Panen Combine Harvester}

Biaya dalam kegiatan usahatani dikeluarkan oleh petani dengan tujuan untuk menghasilkan pendapatan yang tinggi bagi usaha yang dikerjakan, dengan mengeluarkan biaya maka petani mengharapkan pendapatan yang setinggitingginya melalui peningkatan produksi. Biaya dalam kegiatan usahatani terdiri dari biaya tetap (fixed cost) dan biaya variabel (variabel cost). Dalam penelitian analisa usaha diperhitungkan selama 3 tahun usaha berjalan yaitu dari tahun 2013 sampai dengan tahun 2015. Untuk setiap tahunnya terdapat 2 kali waktu penyewaan mesin panen Combine Harvester yaitu pada musim rendeng (Oktober samapi Maret) dan musim gadu (April sampai September). Berikut komponen biaya usaha penyewaan mesin panen Combine Harvester di Desa Karang Mulya Kecamatan Semendawai Timur Kabupaten OKU Timur :

\section{Biaya Tetap}

Biaya tetap (Fixed Cost) adalah biaya yang relatif tetap jumlahnya dan harus dikeluarkan walaupun produk yang dihasilkan banyak atau sedikit dan tidak habis dalam satu kali proses produksi. Dalam hasil penelitian yang dikelompokkan ke dalam biaya tetap (biaya investasi) di antaranya adalah biaya pembelian mesin Combine Harvester, pembuatan gudang dan pembelian roda combine. Analisa biaya dihitung selama 3 tahun usaha berjalan yaitu dimulai dari tahun 2013 sampai dengan awal tahun 2015. Dalam setiap tahunnya terdapat dua kali proses penyewaan mesin combine yaitu musim gadu dan musim rendeng. Berikut komponen biaya tetap usaha penyewaan mesin Combine Harvester :

\begin{tabular}{|c|c|c|c|c|c|}
\hline \multirow{2}{*}{ No } & \multirow{2}{*}{ Komponen Biaya } & \multicolumn{3}{|c|}{ Tahun } & \multirow{2}{*}{ Jumlah } \\
\hline & & 2013 & 2014 & 2015 & \\
\hline 1 & Pembelian Combaine & 370.000 .000 & - & - & 370.000 .000 \\
\hline 2 & Pembuatan Gudang & 50.000 .000 & - & - & 50.000 .000 \\
\hline 3 & Ban Combaine & - & - & 25.000 .000 & 25.000 .000 \\
\hline 4 & Sewa Gudang & 1.333 .334 & 1.333 .334 & 1.333 .334 & 4.000 .002 \\
\hline 5 & Penyusutan Combine & 19.733 .334 & 19.733 .334 & 19.733.334 & 59.200 .002 \\
\hline & Jumlah Biaya Tetap & 441.066 .668 & 21.066 .668 & 46.066 .668 & 508.200 .004 \\
\hline
\end{tabular}

Tabel 2. Biaya Tetap Usaha Penyewaan Mesin Combine Harvester, 2013-2015.

Sumber: Olahan Data Primer, 2015. 
Berdasarkan hasil perhitungan pada tabel diatas diketahui bahwa biaya tetap usaha penyewaan mesin panen padi Combine Harvester digunakan untuk investasi pada awal usaha pada tahun 2013 yaitu digunakan untuk pembelian mesin combine harvester, pembangunan gudang combine, pembelian ban combine pada tahun 2015, sewa gudang dan penyusutan combine yang dihitung dalam setiap kali musim panen yaitu pada Bulan Maret dan Bulan Agustus setiap tahunnya.

Adapun besarnya biaya tetap usaha penyewaan mesin panen combine harvester pada tahun 2013 adalah sebesar Rp 441.066.668. Besarnya biaya tetap usaha penyewaan mesin panen combine harvester pada tahun 2014 adalah sebesar Rp 21.066.668. Besarnya biaya tetap usaha penyewaan mesin panen combine harvester pada tahun 2015 adalah sebesar $\mathrm{Rp}$ 46.066.668. Adapun total biaya tetap usaha penyewaan mesin panen padi Combine Harvester di Desa Karang Mulya selama 3 tahun yaitu dari tahun 2013 sampai dengan tahun 2015 adalah sebesar Rp 508.200.004.

\section{Biaya Variabel}

Biaya tidak tetap (Variable cost) adalah biaya yang sifatnya berubah-ubah yang digunakan sebagai biaya operasional usaha dan biasanya habis dalam satu kali proses. Biaya variabel usaha penyewaan mesin panen padi Combine Harvester terdiri dari biaya operasional digunakan untuk operasional usaha penyewaan mesin panen padi Combine Harvester dan biaya tenaga kerja. Analisa biaya variabel dalam penelitian dihitung selama 3 tahun usaha berjalan yaitu dimulai dari tahun 2013 sampai dengan tahun 2015. Berikut komponen biaya operasional usaha penyewaan mesin panen padi Combine Harvester di Desa Karang Mulya Kecamatan Semendawai Timur Kabupaten OKU Timur :

Tabel 3. Biaya Operasional Usaha Penyewaan Mesin Combine Harvester, 2015.

\begin{tabular}{llrrrr}
\hline \multirow{2}{*}{ No } & \multirow{2}{*}{ Komponen Biaya } & \multicolumn{3}{c}{ Tahun } & \multirow{2}{*}{ Jumlah } \\
\cline { 3 - 4 } & & \multicolumn{1}{c}{2013} & \multicolumn{1}{c}{2014} & \\
\hline 1 & Solar & 18.750 .000 & 27.625 .000 & 31.875 .000 & 78.250 .000 \\
2 & Panbell Kecil (2 Unit) & 170.000 & 350.000 & 400.000 & 920.000 \\
3 & Parbell Besar (4 Unit) & 3.500 .000 & 8.000 .000 & 8.400 .000 & 19.900 .000 \\
4 & Oli Gardan & 720.000 & 740.000 & 800.000 & 2.260 .000 \\
5 & OliHidrolik & 150.000 & 180.000 & 200.000 & 530.000 \\
6 & Gear Bintang & 5.000 .000 & 10.000 .000 & 10.250 .000 & 25.250 .000 \\
7 & Biaya servis dan Las & 2.000 .000 & 4.000 .000 & 4.000 .000 & 10.000 .000 \\
8 & Sewa MobilRolling & 8.000 .000 & 10.000 .000 & 12.000 .000 & 30.000 .000 \\
9 & Telepon & 1.200 .000 & 1.200 .000 & 1.200 .000 & 3.600 .000 \\
\hline & Total Biaya Operasional & 39.490 .000 & 62.095 .000 & 69.125 .000 & 170.710 .000 \\
\hline
\end{tabular}

Sumber: Olahan Data Primer, 2015.

Berdasarkan hasil perhitungan pada tabel diatas diketahui bahwa biaya operasional usaha penyewaan mesin panen padi Combine Harvester digunakan untuk biaya solar, pembelian panbell besar dan kecil, oli, spare part, gear bintang, biaya servis dan perawatan, biaya sewa mobil (rolling) untuk mengantar mesin combine dan biaya telepon.

Adapun besarnya biaya operasional usaha penyewaan mesin panen padi Combine Harvester pada tahun 2013 adalah sebesar Rp 39.490.000. Besarnya biaya operasional usaha penyewaan mesin panen padi Combine Harvester pada tahun 2014 adalah sebesar Rp 62.095.000. Besarnya biaya operasional usaha penyewaan mesin panen padi Combine Harvester pada tahun 2015 adalah sebesar $\mathrm{Rp}$ 69.125.000. Adapun total biaya operasional usaha penyewaan mesin panen padi Combine Harvester di Desa Karang Mulya selama 3 tahun yaitu dari tahun 2013 sampai dengan tahun 2015 adalah sebesar Rp 170.710.000.

Tabel 4. Biaya Tenaga Kerja Usaha Penyewaan Mesin Combine Harvester, 2015.

\begin{tabular}{|c|c|c|c|c|c|}
\hline \multirow{2}{*}{ No } & \multirow{2}{*}{$\begin{array}{c}\text { Komponen } \\
\text { Biaya }\end{array}$} & \multicolumn{3}{|c|}{ Tahun } & \multirow{2}{*}{ Jumlah } \\
\hline & & 2013 & 2014 & 2015 & \\
\hline 1 & Operator & 25.000 .000 & 32.500 .000 & 37.500 .000 & 95.000 .000 \\
\hline 2 & Helper /Kuli & 40.000 .000 & 52.000 .000 & 60.000 .000 & 152.000 .000 \\
\hline
\end{tabular}

\begin{tabular}{lllll} 
Total Biaya Tenaga Kerja $\quad 65.000 .000$ & 84.500 .000 & 97.500 .000 & 247.000 .000 \\
\hline Sumber:
\end{tabular} Sumber: Olahan Data Primer, 2015.

Biaya tenaga kerja usaha penyewaan mesin panen padi Combine Harvester digunakan untuk antara lain untuk membayar operator mesin combine harvester yaitu sebesar Rp 250.000/ha dan membayar tenaga helper atau kuli sebanyak 5 orang dan besarnya biaya helper atau kuli adalah sebesar Rp 400.000/Ha. Besarnya biaya tenaga kerja pada tahun 2013 adalah sebesar Rp 65.000.000. Besarnya biaya tenaga kerja pada tahun 2014 adalah sebesar $\mathrm{Rp}$ 84.500.000. Besarnya biaya tenaga kerja pada tahun 2015 adalah sebesar Rp 97.500.000 sehingga total biaya tenaga kerja dari tahun 2013-2015 adalah $\mathrm{Rp}$ 247.000.000

Tabel 5. Biaya Variabel Usaha Penyewaan Mesin Combine Harvester, 2015.

\begin{tabular}{|c|c|c|c|c|c|}
\hline \multirow{2}{*}{ No } & \multirow{2}{*}{ Uraian } & \multicolumn{3}{|c|}{ Tahun } & \multirow{2}{*}{ Jumbh } \\
\hline & & 2013 & 2014 & 2015 & \\
\hline 1. & Biaya Operasional & 39.490 .000 & 62.095 .000 & 69.125 .000 & 170.710 .000 \\
\hline 2. & Biaya Tenaga Kerja & 65.000 .000 & 84.500 .000 & 97.500 .000 & 247.000 .000 \\
\hline \multicolumn{2}{|c|}{ Total Biaya Variabel } & 104.490 .000 & 146.595 .000 & 166.625 .000 & 417.710 .000 \\
\hline
\end{tabular}

Sumber: Olahan Data Primer, 2015.

Berdasarkan hasil perhitungan pada tabel diatas dapat diketahui bahwa besarnya biaya variabel usaha penyewaan mesin panen padi combine harvester yang terdiri dari biaya operasional dan biya tenaga kerja. Besarnya biaya variabel usaha penyewaan mesin panen padi 
combine harvester pada tahun 2013 adalah sebesar Rp 104.490.000. Besarnya biaya variabel usaha penyewaan mesin panen padi combine harvester pada tahun 2014 adalah sebesar Rp 146.595.00 dan besarnya biaya variabel usaha penyewaan mesin panen padi combine harvester pada tahun 2015 adalah sebesar Rp 166.625.00 sehingga total biaya variabel usaha penyewaan mesin panen padi Combine Harvester di Desa Karang Mulya Kecamatan Semendawai Timur pada tahun 2013 sampai tahun 2015 adalah sebesar Rp 417.710.000.

\section{Biaya Total Produksi}

Biaya total dalam usaha penyewaan mesin panen padi Combine Harvester di Desa Karang Mulya terdiri dari biaya tetap ditambah dengan biaya variabel. Besarnya biaya total yang dikeluarkan oleh responden dapat dilihat pada tabel berikut :

Tabel 6. Biaya Total Usaha Penyewaan Mesin Combine Harvester, 2015.

\begin{tabular}{llrrrr}
\hline \multirow{2}{*}{ No } & \multirow{2}{*}{ Uraian } & \multicolumn{3}{c}{ Tahun } & \multirow{2}{*}{ Jumlah } \\
\cline { 3 - 5 } & & \multicolumn{1}{c}{2013} & \multicolumn{1}{c}{2014} & \multicolumn{1}{c}{2015} & \\
\hline 1. & Biaya Tetap & 441.066 .668 & 21.066 .668 & 46.066 .668 & 508.200 .004 \\
2. & Biaya Variabel & 104.490 .000 & 146.595 .000 & 166.625 .000 & 417.710 .000 \\
\hline & Total Biaya & 545.556 .668 & 167.661 .668 & 212.691 .668 & 925.910 .004 \\
\hline
\end{tabular}

Sumber: Olahan Data Primer, 2015.

Berdasarkan hasil perhitungan pada tabel diatas diketahui bahwa biaya total usaha penyewaan mesin panen combine harvester yang terdiri dari biaya tetap dan biaya variabel pada tahun 2013 sebesar Rp 545.556.668. Biaya total usaha penyewaan mesin panen combine harvester pada tahun 2014 adalah sebesar Rp 167.661.668. Biaya total usaha penyewaan mesin panen combine harvester pada tahun 2015 sebesar Rp 212.691.668 sehingga total biaya produksi usaha penyewaan mesin panen padi Combine Harvester selama 3 tahun dari tahun 2013 sampai dengan tahun 2015 di Desa Karang Mulya Kecamatan Semendawai Timur Kabupaten OKU Timur adalah sebesar Rp 925.910.004.

\section{B. Penerimaan dan Pendapatan}

Penerimaan usaha penyewaan mesin panen padi Combine Harvester diperoleh dari petani yang menyewa combine untuk memanen padi mereka. Biaya sewa biasanya diberikan dalam bentuk bawon dengan pembagian 8:1 artinya dalam setiap 8 karung gabah hasil panen 7 karung untuk pemilik sawah dan 1 karung untuk biaya sewa combine. Responden menjelaskan bahwa dalam satu kali musim panen umumnya luas sawah yang menggunakan combine rata-rata adalah seluas $50 \mathrm{Ha}$. Dalam satu tahun terdapat dua kali waktu panen yaitu panen rendeng pada Bulan Maret dan panen gadu pada Bulan Agustus. Tabel 7. Penerimaan dan Pendapatan Usaha Penyewaan Mesin Combine Harvester, 2015.

\begin{tabular}{llrrrr}
\hline \multirow{2}{*}{ No } & \multicolumn{3}{c}{ Uraian } & \multicolumn{3}{c}{ Tahun } & \multirow{2}{*}{ Jumlah } \\
\cline { 3 - 5 } & & 2013 & 2014 & 2015 & 380 \\
\hline 1 & Luas Panen (Ha) & 100 & 130 & 150 & 9 \\
2 & Jumlah Bawon (Karung Ha) & 9 & 9 & 9 & 3.420 \\
3 & Total Bawon (KarungMT) & 900 & 1.170 & 1.350 & 90 \\
4 & Jumlah GKP (KgKarung) & 90 & 90 & 90 & 307.800 \\
5 & Total GKP (KgMT) & 81.000 & 105.300 & 121.500 & 3.583 \\
6 & Harga GKP (Rp/Kg) & 3.450 & 3.650 & 3.650 & 1.107 .270 .000 \\
7 & Penermaan & 279.450 .000 & 384.345 .000 & 443.475 .000 & \\
8 & Biaya total & 545.556 .668 & 167.661 .668 & 212.691 .668 & 925.910 .004 \\
9 & Pendapatan & $(266.106 .668)$ & 216.683 .332 & 230.783 .332 & 181.359 .996 \\
\hline
\end{tabular}

Sumber: Olahan Data Primer, 2015.

Berdasarkan hasil perhitungan pada tabel diatas diketahui bahwa luas panen pada tahun 2013 adalah seluas $100 \mathrm{Ha}$ dan jumlah bawon untuk setiap hektar adalah sebanyak 9 karung sehingga jumlah bawon seluruhnya adalah sebanyak 900 karung. Adapun jumlah gabah kering panen untuk setiap karungnya rata-rata adalah sebanyak $90 \mathrm{Kg}$ sehingga total jumlah GKP dalam satu tahun adalah sebanyak 81.000. Harga jual rata-rata GKP adalah Rp $3.450 / \mathrm{Kg}$ sehingga diperoleh penerimaan usaha selama tahun 2013 adalah sebesar Rp 279.450.000. Biaya total yang dikeluarkan selama tahun 2013 adalah sebesar $\mathrm{Rp}$ 545.556.668 sehingga diperoleh pendapatan usaha pada tahun 2013 adalah sebesar Rp (266.106.668). Pada tahun 2013 usaha mengalami kerugian karena biaya investasi cukup besar yaitu untuk membeli mesin combaine dan pembangunan gudang.

Luas panen pada tahun 2014 adalah seluas $130 \mathrm{Ha}$ dan jumlah bawon untuk setiap hektar adalah sebanyak 9 karung sehingga jumlah bawon seluruhnya adalah sebanyak 1.170 karung. Adapun jumlah gabah kering panen untuk setiap karungnya rata-rata adalah sebanyak $90 \mathrm{Kg}$ sehingga total jumlah GKP dalam satu tahun adalah sebanyak 105.300. Harga jual rata-rata GKP adalah $\mathrm{Rp} 3.650 / \mathrm{Kg}$ sehingga diperoleh penerimaan usaha adalah sebesar Rp 384.345.000. Biaya total yang dikeluarkan adalah sebesar Rp 167.661.668 sehingga diperoleh pendapatan usaha pada tahun 2014 adalah sebesar Rp 216.683332.

Luas panen pada tahun 2015 adalah seluas $150 \mathrm{Ha}$ dan jumlah bawon untuk setiap hektar adalah sebanyak 9 karung sehingga jumlah bawon seluruhnya adalah sebanyak 1.350 karung. Adapun total jumlah GKP dalam satu tahun adalah sebanyak 121.500. Harga jual rata-rata GKP adalah $\mathrm{Rp} 3.650 / \mathrm{Kg}$ sehingga diperoleh 
penerimaan usaha adalah sebesar $\mathrm{Rp} \mathrm{443.475.000.}$ Biaya total yang dikeluarkan adalah sebesar Rp 212.691.668 sehingga diperoleh pendapatan usaha pada tahun 2015 adalah sebesar Rp 230.783.332. Adapun total pendapatan usaha penyewaan mesin panen padi Combine Harvester selama 3 tahun dari tahun 2013 sampai dengan tahun 2015 di Desa Karang Mulya Kecamatan Semendawai Timur Kabupaten OKU Timur adalah sebesar Rp 181.359.996.

\section{Analisis Kelayakan Usaha}

Analisis kelayakan usaha agribinis adalah upaya untuk mengetahui tingkat kelayakan atau kepantasan untuk dikerjakan dari suatu jenis usaha, dengan melihat beberapa parameter atau kriteria kelayakan tertentu. Suatu usaha dikatakan layak kalau keuntungan yang diperoleh dapat menutup seluruh biaya yang dikeluarkan. Studi kelayakan merupakan bahan pertimbangan dalam mengambil suatu keputusan, menerima atau menolak suatu gagasan usaha yang direncanakan (Ibrahim, 1998).

Tabel 8. Analisis Kelayakan Usaha Penyewaan Mesin Combine Harvester di Desa Karang Mulya Semendawai Timur OKU Timur, 2013-2015.

\begin{tabular}{|c|c|c|c|c|c|}
\hline \multirow{2}{*}{ No } & \multirow{2}{*}{ Biaya dan Manfaa } & \multicolumn{3}{|c|}{ Tahun } & \multirow{2}{*}{ Jumlah } \\
\hline & & 2013 & 2014 & 2015 & \\
\hline 1 & Biaya Tetap & 441.066 .668 & 21.066 .668 & 46.066 .668 & 508.200 .004 \\
\hline 2 & Biaya Variabel & 104.490 .000 & 146.595 .000 & 166.625 .000 & 417.710 .000 \\
\hline 3 & Total Biaya & 545.556 .668 & 167.661 .668 & 212.691 .668 & 925.910 .004 \\
\hline 4 & Penerimaan & 279.450 .000 & 384.345 .000 & 443.475 .000 & 1.107 .270 .000 \\
\hline 5 & Pendapatan & (266.106.668) & 216.683 .332 & 230.783 .332 & 181.359 .996 \\
\hline 6 & NPV & & & & 70.566 .331 \\
\hline 7 & IRR & & & & $42,35 \%$ \\
\hline 8 & Net B/C & & & & 1,313 \\
\hline
\end{tabular}

Sumber: Olahan Data Primer, 2015.

\section{Analisa NPV}

Net Present Value (NPV) atau nilai sekarang bersih adalah analisis manfaat finansial yang digunakan untuk mengukur layak tidaknya suatu usaha dilaksanakan dilihat dari nilai sekarang (present value). Kriteria kelayakan dari usaha ini adalah: proyek layak jika NPV lebih besar dari nol (positif) dan sebaliknya proyek tidak layak jika NPV nilainya lebih kecil dari nol (negatif).

Hasil analisis pada Tabel 8 diperoleh biaya tetap usaha penyewaan mesin combine harvester selama 3 tahun (tahun 2013 sampai 2015) adalah sebesar Rp 508.200.004. Biaya variabel selama 3 tahun adalah sebesar $\mathrm{Rp}$ 417.710.000 sehingga diperoleh biaya total sebesar Rp 925.910.004. Total penerimaan usaha penyewaan mesin panen padi combine harvester selama 3 tahun adalah sebesar Rp 1.107.270.000 sehingga diperoleh total pendapatan usaha selama 3 tahun adalah sebesar Rp 181.359.996.

Dari perhitungan NPV selama tiga tahun usaha yaitu tahun 2013, tahun 2014 dan tahun 2015 dengan tingkat bunga $18 \%$ (NPV df 18\%) maka diperoleh nilai NPV adalah sebesar Rp 70.566.330,56. Berdasarkan analisis diperoleh nilai NPV > 0, Hal ini menunjukan bahwa usaha penyewaan mesin panen padi combine harvester di Desa Karang Mulya Kecamatan Semendawai Timur OKU Timur ini menguntungkan dan layak secara financial untuk diteruskan.

\section{Analisa IRR (Internal Rate of Return)}

IRR menunjukkan kemampuan suatu investasi atau usaha dalam menghasilkan return atau tingkat keuntungan yang bisa dipakai. Kriteria yang dipakai untuk menunjukkan bahwa suatu usaha layak dijalankan adalah jika nilai IRR lebih besar dari tingkat suku bunga yang berlaku pada saat usaha tersebut diusahakan (Gittinger, 1993). Jadi, jika IRR lebih tinggi dari tingkat bunga bank atau lebih tinggi dari Social Oportunity Cost of Capital (SOCC) maka usaha yang direncanakan atau yang diusulkan layak secara finansial untuk dilaksanakan. Jika IRR lebih kecil dari tingkat bunga bank maka usaha yang direncanakan atau yang diusulkan tidak layak secara finansial untuk dilaksanakan.

Berdasarkan perhitungan pada Tabel 8 diperoleh nilai NPV positif (+) adalah sebesar Rp 70.566.330,56 dan nilai NPV negatif (-) terkecil dengan nilai interest $43 \%$ adalah sebesar $\mathrm{Rp}$ (1.204.097). Berdasarkan hasil perhitungan dengan menggunakan Compounding Faktor 18\%, maka diperoleh nilai IRR usaha penyewaan mesin panen combine harvester adalah sebesar $42,35 \%$ yang berarti nilai IRR lebih besar daripada nilai SOCC (Social Opportunity Cost of Capital) atau tingkat suku bunga bank yaitu sebesar $18 \%$. Hal ini menunjukan bahwa usaha penyewaan mesin panen padi combine harvester di Desa Karang Mulya Kecamatan Semendawai Timur menguntungkan dan layak (feasible) secara finansial untuk dikembangkan.

\section{Analisa Net $\mathbf{B} / \mathbf{C}$}

Net Benefit Cost Ratio adalah penilaian yang dilakukan untuk melihat tingkat efisiensi penggunaan biaya berupa perbandingan jumlah nilai bersih sekarang yang positif dengan jumlah nilai bersih sekarang yang negatif, atau dengan kata lain Net $\mathrm{B} / \mathrm{C}$ adalah perbandingan antara jumlah NPV positif dangan jumlah NPV negatif dan ini menunjukkan gambaran berapa kali lipat benefit akan kita peroleh dari cost yang kita 
keluarkan. Kriteria ini memberikan pedoman bahwa suatu proyek akan dipilih apabila nilai (Net $B / C>0)$, sebaliknya bila suatu proyek memberikan nilai $(\mathrm{Net} B / \mathrm{C}<0)$, maka proyek tidak akan diterima (diteruskan).

Tabel 9. Analisa Net B/C Usaha Penyewaan Mesin Combine Harvester di Desa Karang Mulya Semendawai Timur OKU Timur, 2013-2015.

\begin{tabular}{ccc}
\hline No & Tahun & Nilai Present Value Benefit (PVB) \\
\hline 1. & 2013 & $-370.526 .924,52$ \\
2. & 2014 & $255.686 .331,76$ \\
3. & 2015 & $230.783 .332,00$ \\
\hline & Nilai Net B/C & 1,313
\end{tabular}

Sumber: Olahan Data Primer, 2015.

Nilai net $\mathrm{B} / \mathrm{C}$ diperoleh dengan menjumlahkan nilai Present Value Benefit (PVB) positif (+) kemudian hasilnya dibagi dengan nilai PVB negatif (-). Berdasarkan hasil perhitungan, diperoleh nilai Net $\mathrm{B} / \mathrm{C}$ adalah sebesar 1,313. Nilai Net B/C 1,313 artinya setiap Rp 1 yang dikeluarkan untuk modal usaha maka mendapatkan keuntungan bersih sebesar Rp 1,313. Nilai Net B/C 1,31>0 berarti usaha penyewaan mesin panen padi Combine Harvester di Desa Karang Mulya menguntungkan dan layak dikembangkan. Berdasarkan perhitungan analisa NPV, IRR dan Net B/C menunjukan bahwa usaha penyewaan mesin panen padi Combine Harvester di Desa Karang Mulya Kecamatan Semendawai Timur Kabupaten OKU Timur menguntungkan dan layak secara finansial.

\section{IV.KESIMPULAN DAN SARAN}

\section{A. Kesimpulan}

Berdasarnya hasil penelitian dan analisis yang telah dilakukan, maka dapat ditarik kesimpulan sebagai berikut:

1. Biaya total produksi yang dikeluarkan oleh responden dalam usaha penyewaan mesin panen Combine Harvester di Desa Karang Mulya adalah sebesar Rp 871.710.000, penerimaan usaha adalah sebesar $\mathrm{Rp}$ 1.107.270.000 sehingga pendapatan yang diterima adalah sebesar Rp 235.560.000.

2. Usaha penyewaan mesin panen Combine Harvester di Desa Karang Mulya layak (feasible) secara finansial untuk dikembangkan, hal ini dapat diketahui dari perhitungan nilai NPV usaha sebesar Rp
109.848.197, nilai IRR adalah sebesar 58,10\% dan nilai Net B/C sebesar 1,52.

3. Kehadiran mesin panen Combine Harvester dapat membantu memecahkan masalah kekurangan tenaga kerja saat musim panen tiba. Penggunaan Combine Harvester menguntungkan kedua belah pihak yaitu pemberi jasa (pemilik Combine Harvester) dan pengguna jasa (petani pengguna Combine Harvester). Usaha penyewaan mesin Combine Harvester menguntungkan dan layak sehingga memiliki harapan dan prospek yang baik ke depannya.

\section{B.Saran}

Berdasarkan hasil pembahasan dan kesimpulan yang ada di atas maka saran yang dapat diberikan oleh peneliti adalah:

1. Kepada petani dengan kriteria lahan yang memenuhi persyaratan maka diharapkan untuk dapat beralih menggunakan mesin panen padi combine harvester.

2. Dalam rangka meningkatkan produksi padi secara nasional dan mengatasi kelangkaan tenaga kerja di sektor pertanian maka kepada pemerintah perlu diimplementasikan bantuan mesin panen padi combine harvester di daerahdaerah yang mulai mengalami kelangkaan tenaga kerja.

\section{DAFTAR PUSTAKA}

Arsyad, L. 2003. Ekonomi Manajerial. Edisi Kelima. Balai Pustaka. Yogyakarta.

Ahmad, R dan Haryono. 2007. Peluang Usaha Jasa Penanganan Padi Secara Mekanis Dengan Mendukung Industri Persemaian. Prosiding Seminar Nasional Apresiasi Hasil Penelitian Padi 2007.

Anonim. 2002. Petunjuk Teknis Penanganan Pasca Panen, Direktorat Bina Usaha Petani dan pengelolaan Hasil Tanaman Pangan, Direktorat Jendral Pertanian Tanaman Pangan. Jakarta.

Anonim. 2008. Petunjuk Penanganan Pasca Panen. Balai Informasi Pertanian Jawa Timur.

Anonim. 2012. Buku manual Operasi Mesin Padi Combine Harvester. Jakarta.

Barokah, N. I. 2001. Uji Kinerja dan Losses Combine Harvester Type CA 85 ML. Skripsi. Jurusan Mekanisasi Pertanian. Fakultas Teknologi Pertanian. IPB. Bogor.

BPS. 2012. Staistik Ketahanan Pangan. Badan Pusat Statistik Kabupaten OKU Timur. 
Departemen Pertanian. 1993. Pasca Panen Padi. Badan Pendidikan dan Latihan Pertanian.

Gittinger, J. P. 1986. Analisis Ekonomi Proyekproyek Pertanian. UI Press. Jakarta.

Hasibuan, F. 1999. Kajian Teknis dan Ekonomis Pemakaian Head Feed Combine Harvester ( CA 385 EG ) Di Daerah Sukamadi, Kabupaten Subang, Jawa Barat. Skripsi. Jurusan Mekanisasi Pertanian. Fakultas Teknologi Pertanian. IPB. Bogor.

Hernanto, F. 2000. Ilmu Usahatani. Penebar Swadaya. Jakarta.

Ibrahim, Y. 1998. Studi Kelayakan Bisnis. Rineka Cipta. Jakarta.

Kadarsan, T. 2005. Keuangan Pertanian dan Pembiayaan Perusahaan Agribisnis. Gramedia Pustaka Utama. Jakarta.

Manulang. 2005. Analisis Harga. LP3ES. Jakarta.

Manurung dan Rahardja. 2008. Pengantar Ilmu Ekonomi. Penerbit Fakultas EkonomiUniversitas Indonesia. Jakarta.

Miller, R dan Mieners. 2000. Teori Mikroekonomi Intermediate. Edisi Tiga. Raja Grafindo Persada. Jakarta.

Nazir, M. 2003. Metode Penelitian. Cetakan 3. Ghalia Indonesia. Jakarta.

Ricky, W. Ronal dan Ebert, J. 2006. Bisnis Akutansi Manajemen. Erlangga. Jakarta.
Sjarkowi, F dan Marwan. 2004. Manajemen Agribisnis. CV. Baldad Grafiti Press. Palembang.

Sjarkowi, F. 2010. Manajemen Agribisnis. CV. Baldad Grafiti Press. Palembang.

Soekartawi. 2001. Teori Ekonomi Produksi. Rajawali. Jakarta. 2002. Analisis Usahatani. Universitas Indonesia. Jakarta. 2003. Pengantar Agroindustri. Raja Grafindo Persada. Jakarta.

Sugiyono. 2012. Metode Penelitian Bisnis. Cetakan 16. CVAlfabeta. Bandung.

Sukirno, S. 2002. Pengantar Teori Ekonomi Mikro. Edisi Ketiga. PT. Raja Grafindo Persada. Jakarta.

2011. Ekonomi MikroTeori Pengantar. PT Raja GrafindoPersada. Jakarta.

Suparyono dan Setyono, A. 1997. Mengatasi Permasalahan Budidaya Padi. Penebar Swadaya. Jakarta.

Suryodiningrat. 2005. Alsin untuk Pilot Project UPJA. Dinas Pertanian Tanaman Pangan dan Hortikultura Provinsi Kalimantan Selatan.

Teken dan Asnawi. 2005. Teori Ekonomi Mikro. Departemen Ilmu-ilmu Sosial Ekonomi Pertanian. IPB Bogor.

Umar, H. 2003. Studi Kelayakan Bisnis. PT. Raja Grafindo Persada. Jakarta. 